\title{
Can Micro-teaching, Teacher Feedback/Feedforward and Reflective Writing Enhance Pre-service Teachers' Pedagogical Content Knowledge of Grammar in English as a Second Language?
}

\author{
Monica Karlsson \\ Halmstad University, Sweden
}

\begin{abstract}
In the current study, 17 pre-service teachers at (upper) secondary school level studying English as a second language within the Swedish educational system were asked to give two mini-lessons each. Both focused on the teaching of grammar, a subarea towards which many teacher trainees have especially negative feelings. The aims were to explore the extent of the learners' pedagogical content knowledge (PCK) and to investigate if, with the help of micro-teaching, teacher feedback/feedforward and reflective writing, their pedagogical content knowledge could be strengthened further, thus giving these pre-service teachers the boost they need to address grammatical issues in their future L2 classrooms. The findings show that the pre-service teachers' PCK was low in connection with their first mini-lesson, but that with the scaffolding devices implemented it was enhanced, the subject knowledge component proving more easily consolidated than the pedagogical content component. As many as 15 of the 17 teacher trainees displayed positive scores on both components in their second mini-lesson, the learners who did the poorest in their first mini-lesson improving the most. Great individual differences were, however, also detected among the other learners.
\end{abstract}

Index Terms - feedback, feedforward, pedagogical content knowledge (PCK), L2 English grammar, microteaching, written reflection

\section{INTRODUCTION}

Within their education to become L2 English instructors in Sweden, teacher trainees are supposed to acquire knowledge in a wide spectrum of areas. One subarea that continually appears to evoke negative feelings is grammar. Sometimes, at the mere mentioning of the word grammar, although not from all students, sighs and grunts can be heard in the classroom. This interpretation of students' feelings towards grammar is also confirmed in research. As part of Hadjioannou \& Hutchinson's investigation (2010), a number of pre-service teachers were asked questions about their perceptions and knowledge of English grammar as well as their ability to teach in this particular subarea. $23 \%$ of them answered that they did not like grammar, and an additional $45 \%$ that they were unsure of how they felt, thus only $32 \%$ expressing a positive attitude to English grammar in general. Moreover, while $95 \%$ of the participants reported that they remembered having received formal instruction in grammar, none of them thought that they had a very good understanding of the subject area, as many as $87 \%$ of them ranking, on a scale from 1 (low) to 5 (high), their understanding as 3 or below. Also, while most of them believed that they could write and speak quite well, they did not feel very confident in explaining to someone else why a sentence was incorrect and how it should be expressed instead. Here, as many as $93 \%$ of the teacher trainees ranked their ability to teach English grammar as 3 or below. One reason for these negative results may be that during the last few decades a more communicative approach has been taken to the teaching of L2 English, largely neglecting focused grammar instruction (Farrell, 1999).

Moreover, it is very likely that negative perceptions of grammar and grammar teaching are acquired at a young age, transferred subconsciously from those teachers who harbour similar negative attitudes to grammar. Thus locking the minds of teachers-to-be, this vicious circle may hence create insurmountable walls for teacher trainees to adopt new methodological approaches. (Cuban, 1982; Clark \& Peterson, 1986) This, Shulman (1987) claims, appears to especially be the case in subject areas where learners do not possess adequate knowledge.

The present investigation is an attempt to try and break this vicious circle by offering students the content knowledge and pedagogical knowledge they need to gain positive attitudes to L2 English grammar and the teaching thereof.

\section{THEORETICAL BACKGROUND}

\section{A. Pedagogical Content Knowledge (PCK)}

One of the most important qualities of a good teacher is the ability to impart new information to learners in logical and easily comprehensible ways (Darling-Hammond, 2006; Ur, 1996), research showing that there is a clear link between the competence of a teacher and the achievements of his/her students (Ryan \& Cooper, 2004). The question is: What makes a teacher a good teacher? Put differently, "what is it that a teacher knows and is able to do that a specialist 
in the subject matter that the teacher is teaching, no matter how smart they are, doesn't understand and can't do?" (Shulman, 1987, quoted in Berry, Loughran \&Van Driel, 2008, p. 1275).

In 1986, to address what constitutes teacher knowledge, Shulman proposed that the heart of this difference involves "the blending of content and pedagogy into an understanding of how particular topics, problems, or issues are organized, represented, and adapted to the diverse interests and abilities of learners, and presented for instruction" (Shulman, 1986: 8), and he referred to it as 'pedagogical content knowledge' (PCK). More specifically, while content knowledge consists of an understanding of (central) facts, (core) concepts and theories, as well as knowledge of explanatory frameworks within a certain subject area (i.e. an understanding of what is taught), pedagogical knowledge consists of an understanding of matters such as classroom management, lesson structure, and methods of teaching (i.e. an understanding of how to teach and how students learn) (Bararah, 2016), and during the construction and merging of the two the context of instruction as well as students' prior (mis)conceptions need to be taken into account (Grossman, 1990; McDougall, 2005; Mishra \& Koehler, 2006). Hence, teachers' development of PCK involves a substantial change from being able to comprehend subject matter for themselves, to becoming able to elucidate subject matter in new ways, reorganize and partition it, clothe it in activities and emotions, in metaphors and exercises, and in examples and demonstrations, so that it can be grasped by students (Shulman, 1987: 13)

This also indicates that PCK is best acquired through classroom practice (Cochran, DeRuiter \& King, 1993; Hashweh, 1987), be it as pre-service instructors within a teacher program or as qualified teachers in real L2 classrooms. Hence, it is consequently assumed that experienced teachers possess quite elaborated PCK (Clermont, Borko \& Krajcik, 1994).

Within the research literature, despite the fact that there are a great number of studies on teacher knowledge in terms of PCK, there is a dearth of investigations focusing on instructors teaching L2 English. In fact, very little appears to be known about the various components of their PCK (Liu, 2013) at different stages of their career (Abell, 2008), and how these components interact with each other (Liu, 2013). Also, few studies can be found that in addition are concerned with non-native pre-service teachers' L2 English teaching. Bararah (2016), however, provides some valuable insights into this particular field, while addressing two main research questions. Firstly, what PCK, i.e. pedagogical as well as content knowledge, do experienced non-native English teachers display? Secondly, how does their PCK develop over time? Four non-native instructors of English teaching L2 students at junior high school level (second grade), having taught L2 English between six and 20 years, participated in the study. Both classroom observations and individual interviews made up the data of the study, and a comparison was made between the teachers' displayed PCK and their students' achievements. Despite their experience, none of the four informants displayed an overall strong developed PCK. Rather, each teacher had his/her own weaknesses and strengths, indicating that there was room for improvement for all four informants. For example, only two of the participants displayed adequate subject knowledge, which affected their students in negative ways. A lack of subject knowledge of English grammar specifically has been reported in a number of other studies (e.g. Williamson \& Hardman, 1995). Furthermore, while one of the teachers tried to gain information about her learners' prior knowledge of the topic at hand through oral questioning, hence making it possible to adjust her teaching to an appropriate level, the other three did not put any efforts into gaining such information, resulting in the absence of a real foundation for any kind of productive teaching.

In Liu (2013), finally, the PCK of a native speaker, described as an experienced instructor (male), teaching L2 English, was explored. Here too classroom observation and interviews made up the data of the investigation. The study gives some interesting information about the informant's PCK not observed before. Among other things, the results showed that the critical phase to develop PCK is during the early years, when crossing the border from a pre-service student to an in-service teacher takes place. This in turn indicates that teachers who are in the beginning of their careers are in the need of different types of guidance, such as mentoring. Furthermore, the results also showed that the pedagogical part of PCK seems to play a more active role during sessions with students than the content part, but, Liu (2013) claims, it is also less teachable.

\section{B. Micro-teaching}

Introduced at Stanford University in the 1960s (Cruickshank, 1996) with a structure of 'plan, teach, observe, critique' (Bell, 2007; Amobi, 2005), the aim of micro-teaching is to bridge the gap between what teacher trainees are being taught in teacher education programs and the ways in which this knowledge will have to be adapted to real classroom situations. Put differently, the implementation of micro-teaching will help create a link between the pedagogical content knowledge (PCK) teacher trainees have acquired in their teacher education and the pedagogical content knowledge (PCK) they will need in specific contexts with learners of various levels of already established knowledge, be it correct or incorrect. Micro-teaching will hence offer teacher trainees opportunities to reflect on different teaching methods in relation to various topics and student groups (Fernandez, 2010; Putnam \& Borko, 2000) and, based on these reflections as well as peer and teacher feedback, help improve pre-service teachers' teaching skills (Grossman \& McDonald, 2008).

Only a few studies concerned specifically with non-native speakers' micro-teaching of L2 English were found. In Ismail (2011), for instance, focusing on the implementation of micro-teaching of English as a second language (ESL) in relation to young learners, 61 Arab female teacher trainees were included. Within a module focusing on teaching methods, these informants were asked to prepare and give a twenty-minute mini-lesson, to be taught to their fellow students. Additionally, they were requested to reflect in writing as well as orally on their performance. With this set-up, four questions were addressed by the researcher. These were mainly concerned with 1) the effects of micro-teaching on 
pre-service teachers' general language proficiency, 2) to what extent micro-teaching may have an impact on pre-service teachers' teaching competence as well as 3) their preparation skills, and 4) the informants' opinion on the implementation of micro-teaching more generally. A questionnaire, using a five-point scale (5=strongly agree; $1=$ strongly disagree) and organized into the four themes of the research questions, as well as interviews made up the data of the investigation. On all counts, the informants' answers showed positive results, i.e. the opportunity to give a mini-lesson had enhanced their language skills, their skill to understand necessary preparatory steps as well as their teaching competence, making the micro-teaching experience a positive part of their teacher education. Similar positive effects of micro-teaching were observed in Ogeyik (2009) who investigated the attitudes of 57 Turkish teacher trainees studying to become ESL instructors. Along a five-point scale, the informants described micro-teaching to be an effective tool to strengthen their general development and self-confidence as teachers. They further thought that it promoted their skill to develop teaching materials, and enhanced their teaching ability in various courses involving students of different ages and proficiency levels. The great value of micro-teaching for teacher trainees is of course not limited to ESL. Similar observations have been made in, for instance, mathematics (Fernandez, 2010). It appears, however, that in order to make use of the full potential of micro-teaching, it needs to be accompanied by reflection (Ismail, 2011).

\section{Teacher Feedback/Feedforward}

The implementation of feedback, defined as "information provided by an agent (e.g., teacher, peer, book, parent, self, experience) regarding aspects of one's performance or understanding” (Hattie \& Timperley, 2007, p.81) conveying "direct, usable insights into current performance, based on tangible differences between current performance and hoped for performance" (Wiggins, 1993, p. 82) is a natural element of all teacher trainee programs and crucial to the practicum of all pre-service teachers in order for them to progress in their overall trajectory to become qualified and, eventually, experienced and supportive teachers. Lee (2017) considers feedback to be conceptualized in three main steps: 1) feedup (Where am I going?), 2) feedback (How am I going?), and 3) feedforward (Where to next?), the last of which is achieved by implementing the information in step two, thus providing learners with new goals.

Quite a few studies have focused on the nature of feedback/feedforward. Of particular interest to the present study is Akcan \& Tatar (2010). Here the feedback given on the teaching of English as a second language by 52 fourth-year preservice teachers (ages between 20 and 22) studying to become primary and secondary school instructors at a Turkish university was under scrutiny. The data consisted of field notes of classroom observations written by university supervisors, post-lesson sessions (which involved the teacher trainee, a university supervisor and a cooperating field teacher), evaluation sheets, and other types of material such as self-evaluations, journals and video recordings. With the help of this material, the researchers wanted to explore how university supervisors and cooperating teachers approach pre-service teachers when giving feedback, and of what their feedback consisted. The results of the analysis indicated that the feedback provided by the university supervisors most commonly gave the teacher trainees the opportunity to think more deeply about his/her classroom actions. That is, rarely did the supervisors offer immediate advice, but instead repeatedly asked why the student teacher had acted in a certain way, thus encouraging them to reflect on and question their teaching practice as well as make inferences about what improvements can be made. Four areas seemed to have been of main concern: how to increase the teacher trainees' ability to let go of the lesson plan and adapt to unforeseen events, how to engage learners more actively in the lessons, what activities can be implemented in the classroom and, lastly, how to improve the teacher trainees' target language use. The feedback offered by the cooperating teachers, on the other hand, was more advice-oriented, focusing on specific classroom incidents. The cooperating teachers also seemed concerned with establishing a good relationship with the teacher trainees by offering them praise and encouragement.

\section{Reflective Writing}

For the last few decades, reflective practice, which incorporates reflective writing, has been a common and important part of teacher education programs worldwide. Its conducive nature has been shown in numerous studies in a wide spectrum of subjects, including English as a second language (Lee, 2007). It is by placing pre-service teachers at the very center of their own development, contextualizing and hence bridging the gap between theory and practice (Freeman, 2002), that reflection may serve two main purposes. Firstly, if the beliefs held by pre-service teachers are very negative, reflective writing may help to change such attitudes. Secondly, once a transition from negative to more positive beliefs has started, reflective writing may also strengthen learners' pedagogical content knowledge. (Farrell, 1999)

In the research literature, three different types of reflection are discussed: reflection-on-action, reflection-in-action, and reflection-for-action. Reflection-on-action refers to the analyzing and evaluating of past experiences, e.g. what went well and not equally well with a lesson just held, (Farrell, 2007, 2013a, 2014), thus slowly building an awareness of the process that teaching involves (Farrell, 2013a; 2014; Wilson, 2008). Reflection-in-action, on the other hand, involves impromptu decisions that need to be made in the heat of the moment, often proving especially difficult for pre-service teachers due to their lack of previous experience (Farrell, 2007, 2008, 2013b; Schulman, 1986). A parallel can here be drawn with the way a group of musicians work together, Schön explaining that "when good jazz musicians improvise together, they also manifest a 'feel for' their material and they make on the spot adjustments to the sounds they hear" 
(1991, p. 55). Both reflection-on-action and reflection-in-action generally offer opportunities to grow as a teacher (Farrell, 2013a; 2013b; 2014). Reflection-for-action, finally, builds on the experiences accumulated in the past and the present, and incorporates coming up with a plan to improve what did not work before (Wilson, 2008). Wilson points out that these three types of reflection, although they appear neatly linked to different perspectives of time (past, present, and future), there are no true boundaries between them as people constantly tend to weigh different aspects of teaching against each other.

In Farrell (1999), the aim was to explore the attitudes to grammar and the teaching of grammar specifically by asking 34 Singaporean pre-service teachers of ESL (English as a Second Language) to 1) reflect on their past experience of learning English grammar, 2) put together a lesson plan and teach the lesson to a group of secondary student, and 3) reflect on how the lesson went. The answers of five of the 34 participants, representative of the group as a whole, were then selected and analyzed further. Even though the five informants had generally negative experiences of the grammar classroom, the participants' lessons and their reflections made them came to some important realizations. For example, one learner understood that he had not adequately taken the level of the group into account when he planned the lesson. The same student also drew to the conclusion that there is no one way to teach all aspects of grammar in all contexts. Instead, as unforeseen events may often occur, it is important for teachers to understand that there is constantly a need to modify lessons to adapt to the situation at hand.

\section{THE PRESENT STUDY}

\section{A. Research Questions Addressed}

In the present investigation, two main research questions are addressed:

1) What pedagogical content knowledge do Swedish pre-service instructors possess when teaching their first mock grammar mini-lessons in English as a second language?

2) Can Swedish pre-service instructors' pedagogical content knowledge of L2 English grammar be enhanced by means of mini-lessons, teacher feedback/feedforward and reflection, and, if so, to what extent?

To the present author's knowledge, no other study has specifically focused on pre-service students' pedagogical content knowledge of L2 English grammar while simultaneously implementing micro-teaching, feedback/feedforward and reflective writing as scaffolding devices.

\section{B. Informants}

A total number of 17 students participated in the present investigation, all of whom were studying to become either upper secondary school instructors (seven informants, teaching age levels 16-18) or secondary school instructors (ten informants, teaching age levels 13-15) within the Swedish school system ${ }^{1}$. All of them were studying English, as well as one (upper secondary level) or two other subjects (secondary level): history, religion or Swedish. For three students (S2, S3 and S5), English was their second subject within the program, the rest taking English as their first subject. Furthermore, while 16 of the learners were native Swedes, one came from a different linguistic background (S1). However, he arrived in Sweden at a very young age and his Swedish therefore displayed a native-like level. In addition to summarizing the above and offering the informants' gender and age ${ }^{2}$, Table 1 also supplies information about the learners' achievements on the two grammar modules as well as the subcourse in second language acquisition (SLA) relevant to the present study, all of which will be described in more detail in the subsection that follows.

\footnotetext{
${ }^{1}$ In Sweden, secondary school teachers study for four to four and a half years, while the training program for upper secondary school teachers involves five years.

${ }^{2}$ The age given is when the students took their first grammar test.
} 
TABLE 1.

INFORMATION ABOUT THE INFORMANTS

\begin{tabular}{|c|c|c|c|c|c|c|c|}
\hline \multirow[t]{2}{*}{ Student } & \multicolumn{2}{|c|}{ Gender } & \multirow[t]{2}{*}{ Age } & \multirow[t]{2}{*}{ Level } & \multirow{2}{*}{$\begin{array}{l}\text { Final grade - } \\
\text { Grammar } 1\end{array}$} & \multirow{2}{*}{$\begin{array}{l}\text { Final grade SLA } \\
\text { (course work/class test) }\end{array}$} & \multirow{2}{*}{$\begin{array}{l}\text { Final Grade - } \\
\text { Grammar } 2\end{array}$} \\
\hline & $\mathrm{F}$ & $\mathrm{M}$ & & & & & \\
\hline S1 & & $\mathrm{X}$ & 22 & upper secondary school & VG & VG/G & $\mathrm{G}$ \\
\hline $\mathrm{S} 2$ & $\mathrm{X}$ & & 21 & upper secondary school & VG & $\mathrm{G}$ & VG \\
\hline S3 & $\mathrm{X}$ & & 24 & upper secondary school & VG & $\mathrm{G} / \mathrm{G}$ & VG \\
\hline S4 & $\mathrm{X}$ & & 26 & upper secondary school & G & not done & $\begin{array}{l}\mathrm{U}, \text { still not } \\
\text { completed }\end{array}$ \\
\hline $\mathrm{S}^{3}$ & & $\mathrm{X}$ & 21 & upper secondary school & VG & $\mathrm{G} / \mathrm{G}$ & $\mathrm{VG}$ \\
\hline S6 & & $\mathrm{X}$ & 24 & upper secondary school & VG & G/VG & G \\
\hline S7 & & $\mathrm{X}$ & 20 & upper secondary school & $\mathrm{U}$, then $\mathrm{G}$ & VG/U, then $\mathrm{G}$ & $\mathrm{G}$ \\
\hline S8 & & $\mathrm{X}$ & 20 & secondary school & $\mathrm{G}$ & $\mathrm{G} / \mathrm{G}$ & $\mathrm{G}$ \\
\hline S9 & $\mathrm{X}$ & & 19 & secondary school & VG & $\mathrm{G} / \mathrm{U}$, then $\mathrm{G}$ & VG \\
\hline S10 & $\mathrm{X}$ & & 19 & secondary school & VG & $\mathrm{G} / \mathrm{G}$ & VG \\
\hline S11 & & $\mathrm{X}$ & 19 & secondary school & $\mathrm{U}, \mathrm{U}, \mathrm{U}$, still not completed & $\mathrm{G} / \mathrm{U}, \mathrm{U}$, still not completed & $\begin{array}{l}\text { U, still not } \\
\text { completed }\end{array}$ \\
\hline $\mathrm{S} 12$ & & $\mathrm{X}$ & 21 & secondary school & VG & $\mathrm{G}$ & $\mathrm{U}$, then $\mathrm{G}$ \\
\hline S13 & $\mathrm{X}$ & & 34 & secondary school & $\mathrm{G}$ & VG/VG & $\mathrm{G}$ \\
\hline S14 & $\mathrm{X}$ & & 20 & secondary school & G & $\mathrm{G} / \mathrm{U}$, then $\mathrm{G}$ & $\mathrm{U}$, then $\mathrm{G}$ \\
\hline $\mathrm{S} 15^{4}$ & $\mathrm{X}$ & & 40 & secondary school & VG & VG/VG & $\mathrm{G}$ \\
\hline S16 & & $\mathrm{X}$ & 23 & secondary school & G & VG/G & $\mathrm{G}$ \\
\hline S17 & $\mathrm{X}$ & & 27 & secondary school & $\mathrm{G}$ & $\begin{array}{l}\text { not done/U, } \\
\text { still not completed }\end{array}$ & U, U, still not completed \\
\hline
\end{tabular}

\section{The English Grammar Courses and the Second Language Acquisition Module Part of the Informants' Teacher Education}

Within English at the university in which the present data were collected, irrespective of whether the students are studying to become secondary or upper secondary school instructors, they do two grammar modules. Together with educational science, in which they are given a general introduction to what it entails to work as a teacher, the students do their first grammar course during their first term. This module starts by discussing general grammar in terms of word classes, phrases and clause elements. Once English grammar becomes the focus, the course highlights differences between the English and Swedish language, and deals with (mis)conceptions prospective students (may) have in these respects, yet it does not disregard other non-contrastive matters that are usually considered difficult to master. In many ways, this subcourse can best be described as a traditional, proficiency-oriented module, but it also provides the students with tips on how to approach the different areas included in their future classrooms. The test given at the end of this course, however, focuses only on their grammatical knowledge.

Their second grammar module is done during their second term. This subcourse has three main aims. Firstly, the module is to consolidate the knowledge acquired during the first subcourse. Secondly, while a few theoretical issues are addressed in the first grammar module, such as the difference between prescriptive and descriptive grammar, the learners are during the second module presented with more in-depth theory, all linked to the module in second language acquisition mentioned in the previous subsection. Finally, in the third part the students are asked to implement what they have learnt during both grammar courses (as well as the SLA module) by giving mini-lessons (more about these can be found under method below). All three parts are considered in the final grade given for this module.

As mentioned above, all students also took a course in SLA. This module consists of one theoretical part in which the students are presented with a number of different theories, and one practical part in which they are to give mini-lessons based on what they have learnt. In the latter part, the instructor usually encourages students to present their mini-lessons in an engage-study-activate pattern. That is, in the first step the curiosity of the audience is to be raised, in the second step the subject area at hand is to be presented in more detail, and in the final step the class is to be set to work by providing them with some sort of material. While not all students are asked to focus on grammar in their mini-lessons, as a wide variety of fields are covered in the SLA module, some actually are. For this module, the students receive two grades, one focusing on course work (practical part) and one on a final test (theoretical part).

At the time of the collection of the data for the present investigation, the syllabi for English were being revised. This meant that whereas some students did the SLA module parallel with their first grammar course (Students 2, 3 and 5, see Table 1), others did it in connection with their second grammar module.

\section{Method}

As mentioned above, as part of the second grammar module the informants were asked, on two separate occasions, to give two mini-lessons each, both lasting between 10 and 15 minutes. (Regrettably, the time allotted for the grammar module did not permit more than two mini-lessons per student. A series of mini-lessons would of course have been

\footnotetext{
${ }^{3}$ This student did the very first presentation.

${ }^{4}$ This student started on the secondary school program within which she did the English modules, she then transferred to the upper secondary program.
} 
preferred.) While the topic of the first one was assigned by the present author, and selected from the areas that were addressed during the students' first grammar course, the students were allowed to choose freely, among the same topics, for their second mini-lesson. Three of the students actually asked to do the same topic twice, either because they did not feel their performance during the first mini-lesson was satisfying (S16) or because they wanted to increase the level of difficulty during their second mini-lesson (S10, S13). The students were told that, although their fellow classmates and the present author would be their audience, they should adjust the mini-lesson to the educational level they would be teaching in the future, and that they could either choose to imagine that this was the first time they addressed this particular area or that, prior to the current session, they had already introduced the topic in a previous session. Before they started their mini-lesson, they were asked to disclose which of the two options they had decided on. As the time allotted for each student was very limited, they were also instructed not to try to cover everything in the area assigned/chosen, but rather to focus on one or a few aspects, and to start their mini-lessons by clearly stating what the focus and goal of the lesson were. Moreover, to imitate what goes on in a real classroom, two students in the audience were assigned to ask at least one question each, which could either be concerned with something they truly did not understand or be a mock question. The other students were also encouraged to ask questions.

In connection with their oral presentation, the students were also required to construct a written exercise, to be handed out to all the students in the audience. They were told that there would not be time for them to ask the audience to work through the entire exercise, nor would there be time to go through it all. Instead they should select a few questions on the work sheet that could be addressed in class.

Due to scheduling, half of the students (S1, S3, S5, S7, S8, S9, S13, S14, S15) had only one week to prepare for their first mini-lesson, while the rest (S2, S4, S6, S10, S11, S12, S16, S17) had two weeks. All students had ample time to prepare for their second mini-lesson, which for the former group took place three weeks after their first one, and for the latter group one week after that. Admittedly, it is difficult to determine the effects of these differences in time allotment, if any. However, none of the students expressed concern about their being too little time for the planning of their minilessons.

After each mini-lesson, the presenter received immediate feedback/feedforward by his/her peers and, in more depth, by the present author, all in order for him/her to be able to improve for the next mini-lesson and for future real-life endeavors.

Finally, during the introduction to the second grammar module, the students were informed that when assessing their mini-lessons and material, the present author would consider pedagogical knowledge as well as content knowledge. More specifically, the following aspects were decided on:

Pedagogical knowledge:

1) being able to create a positive atmosphere that will promote learning

2) being able to involve the whole audience

3) displaying ability to give an interesting introduction to the topic assigned/chosen in accordance with the practiced pattern of engage-study-activate and to state the purpose clearly

4) being able to let go of the physical lesson plan to have eye contact with the audience

5) being able to show confidence in front of the whiteboard

6) continually checking that the audience have understood what is being presented in the mini-lesson and exercise

7) displaying ability to uphold a 'flow' to the mini-lesson so that no awkward breaks occur during which the audience may lose interest

8) being able to give adequate instructions for the exercises

9) being able to adjust the mini-lesson and matters surrounding it to unforeseen events

10) in the written reflection, displaying an understanding of what was already good and/or what improvement/s can be made from a pedagogical point of view

Content knowledge:

1) displaying confidence of general content knowledge of the topic assigned/chosen

2) displaying confidence in incorporating content of the mini-lesson on the right educational level

3) displaying confidence of content knowledge during mini-lesson (including being able to predict errors typically made within the area)

4) displaying confidence of content knowledge when responding to questions

5) displaying confidence in incorporating content of the exercise on the right educational level

6) displaying confidence of content knowledge in the material produced (including being able to predict errors typically made within the area)

7) displaying confidence in separating between basic knowledge and more advanced knowledge and/or exceptions

8) displaying confidence of content knowledge of the material produced when going through it (including being able to spot errors made by the learners and being able to explain their sources)

9) displaying confidence in aligning the content of the mini-lesson with the content of the exercise

10) in the written reflection, displaying an understanding of what was already good and/or what improvement/s can be made from a content point of view 
For each of the 20 aspects listed above, each student was judged along a three-point scale:

+1 pass, i.e. the student would manage in front of a real class

0 undecided, i.e. the student might manage in front of a real class, but it is questionable

-1 fail, i.e. the student would not manage in front of a real class

This means that the highest and lowest scores for pedagogical as well as content knowledge respectively are +10 and -10 . Thus, to give an example, if, on pedagogical knowledge, a student receives -1 on each of the first five aspects (=-5), then +1 on each of the following three aspects $(=+3)$ and 0 on the last two $(=0)$, it will yield a total of -2 points $(-5+3+0)$ on that part. If, on content knowledge, the same student receives +1 on the first seven aspects $(=+7)$ and -1 on each of the rest (=-3), it will yield a total of +4 points (+7-3). If the PCK for that student is then calculated it will consequently yield a total of +2 points $(-2+4)$. The total PCK for all 17 students is $+340,+170$ for pedagogical and subject knowledge respectively.

It here needs to be pointed out that, inevitably, there may be elements of subjectivity in the judging of the absence/presence of these aspects. However, the great experience of the present author - more than 20 years as a teacher educator - ensures to minimize such a risk.

\section{E. Reflections}

After the students had given their mini-lessons they were asked to reflect in writing. One reflection was concerned with the oral part and one with the written exercise. In both cases, the informants were asked to give presentations of what they had done in class and discuss their strong and weak points, pedagogically as well as content-wise, while also considering the feedforward they had received from their peers and the present author. Put differently, the students were asked to offer reflection-on-action, i.e., giving accounts of how the mini-lessons went, as well as reflection-for-action, i.e., evaluating and providing insights for future teaching. (Reflection-in-action was instead made part of the 10 aspects of pedagogical knowledge listed above (being able to adjust the mini-lesson and matters surrounding it to unforeseen events). About 11/2 A4-pages (size 12, spacing 1) for each reflection were requested of the students.

\section{F. Questionnaire}

Lastly, after the completion of the course, the informants were requested to answer a questionnaire focusing on their perceived value of 1) their own mini-lessons, 2) having to listen to their peers' mini-lessons, 3) their teacher's feedforward and 4) their written reflections. The informants' answers were given along a five-point scale (from 'not at all valuable' to 'very valuable'), and divided into pedagogical aspects and content aspects in all four cases.

The students asked that they be able to answer this questionnaire anonymously, and consequently no possible correlations between individual answers and teaching performance can be explored in the result section. However, the students' answers will be considered on a group level.

\section{RESULTS AND DiSCUSSION}

In the current subsection, the pedagogical content knowledge displayed by the informants in connection with their two micro-teaching experiences and the accompanied feedback/feedforward and reflective writing will be presented and discussed. Table 2 offers information of the learners' PCK in connection with their first mini-lesson. During this initial link between the theory and practice of L2 English grammar, it is clear that the students' total PCK (20.29\%) is relatively low, far from what is expected of full-fledged teachers. Being only in their second term of their training program, this is, however, not so strange, especially in the light of the fact that, as discussed in theoretical background, even experienced teachers may not have developed full PCK competence (Bararah, 2016). Table 2 further shows that, at this point in time, the learners' knowledge of the subject matter at hand does not yet match (14.12\%) their skill to convey it to an audience $(26.47 \%)$. There are, however, great individual differences. These can be seen in Table 3 . Here the learners' pedagogical knowledge is indicated along the vertical axis, while their content knowledge is displayed along the horizontal axis. The further up in the top right-hand corner the students are found, the more PCK they possess; the further down in the bottom left-hand corner, the less PCK they possess. Moreover, if occurring in the top left-hand quarter, the students' content knowledge is developed to varying degrees (+) but they lack pedagogical knowledge (-), whereas the opposite is true if occurring in the bottom right-hand quarter. To exemplify, student 13 achieved a total of +7 points for her pedagogical knowledge and a total of +3 points for her subject knowledge, thus ending up in the top right-hand quarter.

TABLE 2.

The SEVEnTEen STUdents' PCK In CONNECTION With THEIR FiRST Mini-Lesson

\begin{tabular}{|l|l|l|l|}
\hline & Pedagogical knowledge & Subject knowledge & Total PCK \\
\hline First mini-lesson & $26.47 \%(=45 / 170)$ & $14.12 \%(=24 / 170)$ & $20.29 \%(=69 / 340)$ \\
\hline
\end{tabular}


TABLE 3.

THE STUDENTS' INDIVIDUAL PCK AT THEIR FIRST MINI-LESSON.

Vertical axis: pedagogical knowledge; Horizontal axis: subject knowledge.

\begin{tabular}{|c|c|c|c|c|c|c|c|c|c|c|c|c|c|c|c|c|c|c|c|c|}
\hline$(-) 10$ & -9 & -8 & -7 & -6 & -5 & -4 & -3 & -2 & -1 & 0 & 1 & 2 & 3 & 4 & 5 & 6 & 7 & 8 & 9 & 10 \\
\hline 9 & & & & & & & & & & & & & & & & & & & & 9 \\
\hline 8 & & & & & & & & & & & & & & & & & & & & 8 \\
\hline 7 & & & & & & & & & & & & & S13 & & & & S3 & S10 & & 7 \\
\hline 6 & & & & & & & & & & & S1 & & & & & & S2 & & & 6 \\
\hline 5 & & & & & & & & & & & & & S7 & & S9 & & & & & 5 \\
\hline 4 & & & & & S16 & & & & & & & & S14 & & & & & & & 4 \\
\hline 3 & & & & & & & & & & & & S11 & & S15 & & & & & & 3 \\
\hline 2 & & & & & & & & & & & & & & & $\mathrm{~S} 12$ & & & & & 2 \\
\hline 1 & & & & & & & & & & & & & & & & & & & & 1 \\
\hline 0 & & & & & & & & & & & & & S4 & & & & & & & 0 \\
\hline-1 & & & & & & & S5 & S8 & & & & & & & & & & & & -1 \\
\hline-2 & & & & & & & & & & & & & & & & & & & & -2 \\
\hline-3 & & & & & & & & & & & & & & & & & & & & -3 \\
\hline-4 & & & S6 & & & & & & & & & & & & & & & & & -4 \\
\hline-5 & & & & & & & & & & & & & & & & & & & & -5 \\
\hline-6 & & & & & & & & & & & & & & & & & & & & -6 \\
\hline-7 & & & & & & & & & & & & & & & & & & & & -7 \\
\hline$-8 \mathrm{~S} 17$ & & & & & & & & & & & & & & & & & & & & -8 \\
\hline-9 & & & & & & & & & & & & & & & & & & & & -9 \\
\hline-10 & -9 & -8 & -7 & -6 & -5 & -4 & -3 & -2 & -1 & 0 & 1 & 2 & 3 & 4 & 5 & 6 & 7 & 8 & 9 & $(-) 10$ \\
\hline
\end{tabular}

Eleven of the 17 informants display positive PCK values, for pedagogical as well as subject knowledge, and one student (S4) is on the very verge of doing so. Even within this group, there are, however, great individual differences. For instance, whereas the mini-lessons given by S2, S3, and especially S10 were (comparatively) close to being able to be conducted as is in front of real students, most of the other teacher trainees displayed weaknesses in either of the two components or both. (The fact that S2 and S3 studied Swedish before English may have contributed to them performing in such an advanced manner, as they within that course also practiced teaching in front of their peers.)

Four learners (S5, S6, S8, and S17), on the other hand, received negative PCK scores for both components, where especially student 17 performed very poorly. It should here be noted that S5 gave the very first mini-lesson, thus not being able to benefit from any feedback/feedforward given to the other students (see Footnote 3 ).

Only one learner (S16) received a negative score for content knowledge, while achieving a positive score for his pedagogical skills. It is here interesting to observe that no students displayed the opposite pattern.

There also appears to exist some correlation between PCK achievement and completion of the program. For instance, four of the five students not found in the top right-hand quarter in fact later dropped out. Moreover, while all three of the students who performed the best (S2, S3, and S10) finished their education, several of those students who just barely ended up in the top right-hand quarter did not. That is, while teaching a mini-lesson may generally help enhance teacher trainees' PCK, it may also, as hinted at in the written reflections, help some learners realize that teaching is really not for them.

Presented in order of frequency, starting with the highest score, Table 4 offers an overview of the pedagogical and subject knowledge aspects that the students succeeded/did not succeed in implementing in connection with their first mini-lesson.

TABLE 4.

AsPects Of Pedagogical Knowledge And Content Knowledge Respectively At The First MinI-LESSON, PRESENTEd In ORdER OF FREQUENCY, STARTING With THE HigheST PCK SCORE

\begin{tabular}{|l|l|l|l|l|}
\hline \multicolumn{4}{|c|}{ First mini-lesson } \\
\hline Aspect no & Pedagogical knowledge & Aspect no & Subject knowledge \\
\hline 10$)$ & +15 & & $2)$ & +7 \\
\hline 1$)$ & +11 & $5)$ & +7 \\
\hline 6$)$ & +6 & $10)$ & +7 \\
\hline 2$)$ & +5 & $1)$ & +6 \\
\hline 5$)$ & +5 & $6)$ & +6 \\
\hline 3$)$ & +3 & $3)$ & +4 \\
\hline 8$)$ & +3 & $4)$ & +1 \\
\hline 7$)$ & 0 & $8)$ & -2 \\
\hline 4$)$ & -1 & $9)$ & -5 \\
\hline 9$)$ & -2 & $7)$ & -7 \\
\hline
\end{tabular}

As can be seen, for both components, the learners were comparatively accomplished when it came to discussing pros and cons of their mini-lessons, hence displaying evidence of an understanding of what changes could be made to improve their second mini-lesson (aspect 10). They were also quite accomplished when it came to creating a positive atmosphere that will promote learning (aspect 1, pedagogical knowledge) and incorporating content (mini-lesson as well as exercise) on the right educational level (aspects 2 and 5, subject knowledge). On the other hand, they displayed 
an inability to, for instance, let go of the physical lesson plan and to adjust their mini-lesson to unforeseen events (aspects 4 and 9, pedagogical knowledge), the latter of which indicates a lack of reflection-in-action which is normally difficult for unexperienced teachers (Farrell, 2007, 2008, 2013b; Shulman, 1986). They were also unable to, for example, separate clearly between basic and more advanced knowledge and align the content of the mini-lesson with the content of the exercise (aspects 7 and 9, subject knowledge).

Table 5 gives information of the learners' PCK in connection with their second mini-lesson, which can be compared with what they achieved in their first mini-lesson (see Table 2). It is obvious that the scaffolding in the form of minilessons, feedback/feedforward and written reflections helped strengthen the students' total PCK (from 20.29\% to $42.94 \%$, i.e. 22.65 percentages), their pedagogical knowledge (from $26.47 \%$ to $37.65 \%$, i.e. 11.18 percentages) as well as their subject knowledge (from $14.12 \%$ to $48.24 \%$, i.e. 35.12 percentages) being affected positively. This is encouraging since, Liu (2013 claims, the critical phase to acquire PCK is during the early years of training. Moreover, as the reader can see, this was especially the case with the latter component, the students now consolidating their grammatical knowledge. This also tallies with Liu (2013) who states that the subject component is the more teachable of the two.

According to their own answers to the questions on the survey, the teacher trainees seemed to have gained most of this PCK from the teacher's feedback/feedforward and their own mini-lessons, and the least from their written reflections (see Table 6). As evidenced by what the majority of the students wrote, the fact that their teacher had asked them why they had made certain choices in the planning of the mini-lessons, which in turn made them think more deeply on how they had approached the task set before them, and given them clear advice on how different parts could be improved were the main reasons why the teacher's feedback/feedforward was so useful to them. This agrees with what was observed in Akcan \& Tatar (2010), presented in the theoretical background. Furthermore, it seemed that some students felt that they just rehashed in their reflections what they had already learned in class.

TABLE 5.

THE SEVENTEen STUdents’ PCK In CONNECTION With THEIR SECOND Mini-LeSSON

\begin{tabular}{|l|l|l|l|}
\hline & Pedagogical knowledge & Subject knowledge & Total PCK \\
\hline Second mini-lesson & $37.65 \%(=64 / 170)$ & $48.24 \%(=82 / 170)$ & $42.94 \%(=146 / 340)$ \\
\hline
\end{tabular}

TABLE 6.

THE STUDENTS' Answers (AVERAGE SCORE) TO THE QUESTIONNAIRE

\begin{tabular}{|l|l|l|l|l|l|l|}
\hline $\begin{array}{l}\text { To what extent did your own } \\
\text { mini-lessons help improve } \\
\text { your... }\end{array}$ & $\begin{array}{l}\text { To what extent did your fellow } \\
\text { students' mini-lessons help improve } \\
\text { your... }\end{array}$ & $\begin{array}{l}\text { To what extent did your written } \\
\text { reflections help improve your... }\end{array}$ & $\begin{array}{l}\text { To what extent did your teacher's } \\
\text { feedback help you improve your... }\end{array}$ \\
\hline $\begin{array}{l}\text { pedagogical } \\
\text { knowledge }\end{array}$ & $\begin{array}{l}\text { subject } \\
\text { knowledge }\end{array}$ & $\begin{array}{l}\text { pedagogical } \\
\text { knowledge }\end{array}$ & $\begin{array}{l}\text { subject } \\
\text { knowledge }\end{array}$ & $\begin{array}{l}\text { pedagogical } \\
\text { knowledge }\end{array}$ & $\begin{array}{l}\text { subject } \\
\text { knowledge }\end{array}$ & $\begin{array}{l}\text { pedagogical } \\
\text { knowledge }\end{array}$ \\
\hline 4.31 & 4.62 & 3.94 & 3.97 & 3.50 & $\begin{array}{l}\text { subject } \\
\text { knowledge }\end{array}$ \\
\hline
\end{tabular}

Moreover, as shown in Table 7 (which should be interpreted in the same way as Table 3), it was the students who did the poorest at the first mini-lesson that improved the most. According to these students' written reflections, it appears they had all been made acutely aware of the great knowledge gap between themselves and their fellow students, this thus being the main incentive for them wanting to improve before giving their second mini-lesson. Some of the students who appeared in the top left-hand quarter already in connection with their first mini-lesson also progressed, while a few in fact regressed slightly. Regression is perhaps not so strange considering the fact that each grammatical subarea is unique, not only from a content perspective of course, but from a pedagogical perspective too. That is, what works pedagogically for one subarea does not necessarily work for all subareas. As pointed out in the theoretical background, this was one of the lessons learned in Farrell (1999). Another reason for this regression may be that some subject matters are inherently more difficult to master and teach than others. 
TABLE 7.

THE STUDENTS' INDIVIDUAL PCK AT THEIR SECOND Mini-LESSON.

Vertical AXIS: Pedagogical Knowledge; Horizontal AXIS: Subject Knowledge

\begin{tabular}{|l|l|l|l|l|l|l|l|l|l|l|l|l|l|l|l|l|l|l|l|l|l|l|}
\hline$(-) 10$ & -9 & -8 & -7 & -6 & -5 & -4 & -3 & -2 & -1 & 0 & 1 & 2 & 3 & 4 & 5 & 6 & 7 & 8 & 9 & 10 \\
\hline 9 & & & & & & & & & & & & & & & & & & & & 9 \\
\hline 8 & & & & & & & & & & & & & & & & & & & & 8 \\
\hline 7 & & & & & & & & & & & & & & & & S7 & & S13 & & S3 & 7 \\
\hline 6 & & & & & & & & & & & & & & & & & & & & 6 \\
\hline 5 & & & & & & & & & & & & & & & S2; S16 & & S9 & & & 5 \\
\hline 4 & & & & & & & & & & & S1 & & & & S14 & & S11 & S10 & & 4 \\
\hline 3 & & & & & & & & S8 & & & & & S12 & & & & & & & 3 \\
\hline 2 & & & & & & & & & & & & & S4 & & & & S15 & & & 2 \\
\hline 1 & & & & & & & & & & & & & & S6; S17 & & & & & & 1 \\
\hline 0 & & & & & & & & & & & & & & S5 & & & & & & 0 \\
\hline-1 & & & & & & & & & & & & & & & & & & & & -1 \\
\hline-2 & & & & & & & & & & & & & & & & & & & & -2 \\
\hline-3 & & & & & & & & & & & & & & & & & & & & -3 \\
\hline-4 & & & & & & & & & & & & & & & & & & & & -4 \\
\hline-5 & & & & & & & & & & & & & & & & & & & -5 \\
\hline-6 & & & & & & & & & & & & & & & & & & & & -6 \\
\hline-7 & & & & & & & & & & & & & & & & & & & -7 \\
\hline-8 & & & & & & & & & & & & & & & & & & & & -8 \\
\hline-9 & & & & & & & & & & & & & & & & & & & & -9 \\
\hline-10 & -9 & -8 & -7 & -6 & -5 & -4 & -3 & -2 & -1 & 0 & 1 & 2 & 3 & 4 & 5 & 6 & 7 & 8 & 9 & $(-) 10$ \\
\hline
\end{tabular}

Table 8, finally, offers an overview of the aspects the students managed to implement in connection with their second mini-lesson, again starting with the most frequent one. As the reader can see, for the aspects of pedagogical knowledge considered, both those mastered well (e.g. 1 and 10) and those receiving low scores (e.g. 4 and 9) remain approximately the same as in the first mini-lesson. For the aspects of subject knowledge considered, 2 and 10 are still those that received high scores, but the students now also display greater confidence in the material they were asked to produce (mini-lesson as well as exercise). Also, aspects 7 (separating between basic and more advanced knowledge) and 8 (displaying confidence in going through the material produced in class) still appear difficult to acquire, but the learners now seem to have gained a better understanding of aligning the content of the mini-lesson with the content of the exercise, obviously linked to their better understanding of what to focus on in the complementary exercise as a whole.

TABLE 8.

Aspects Of Pedagogical KNowledge And Content KNOWLEdge ResPeCtively At The SECOND Mini-LESSON, PRESENTEd In ORdER OF FREQUENCY, STARTING WITH THE HigheSt PCK SCORE

\begin{tabular}{|c|c|c|c|}
\hline \multicolumn{4}{|c|}{ Second mini-lesson } \\
\hline Aspect no & Pedagogical knowledge & Aspect no & Subject knowledge \\
\hline 10) & +17 & 3) & +14 \\
\hline 1) & +12 & 2) & +13 \\
\hline 3) & +9 & 6) & +13 \\
\hline 2) & +8 & 10) & +9 \\
\hline 5) & +8 & 5) & +7 \\
\hline 6) & +5 & 9) & +7 \\
\hline 8) & +5 & 1) & +6 \\
\hline 4) & 0 & 4) & +1 \\
\hline 7) & 0 & 8) & -2 \\
\hline 9) & 0 & 7) & -7 \\
\hline
\end{tabular}

Table 8 shows that even after two sessions of micro-teaching accompanied by teacher feedback/feedforward and written reflection, there are aspects of PCK that are difficult to develop. Considering the pedagogical component, which according to Liu (2013) is the more challenging of the two, it appears that, for example, making impromptu decisions, dealing with unforeseen events, and 'freestyling' are especially difficult aspects to master. That is, reflecting in action seems considerably more difficult than reflecting on action or reflecting for action. From a subject point of view, it appears that it is the weighing of content against the knowledge level of each learner that causes most concern (aspects 7 and 8). These subcomponents may therefore need special attention in ESL teacher education programs. However, needless to say, with more experience, novice teachers will slowly be able to display increasingly more confidence, even with the more elusive aspects of the topic at hand and the teaching thereof.

\section{SUMMING UP}

In the present investigation, 17 Swedish pre-service teachers at (upper) secondary school level studying English as a second language were asked to give two mini-lessons each, both focusing on grammar. Offered teacher feedback/feedforward and requested to reflect in writing after their micro-teaching, the learners enhanced their total PCK, both components - pedagogical and especially content knowledge - displaying higher scores during the second mini-lesson than the first one. It was here observed that it was the students who performed the poorest in connection 
with their first mini-lesson that progressed the most. Great individual differences were also detected among the other learners.

However, some of the aspects of the learners' PCK remained difficult to attain even after treatment, a few informants regressing slightly between the first and second mini-lesson. This is perhaps not so strange, considering that the majority of the teacher trainees were faced with completely new subareas the second time around, the students thus learning that not all pedagogical approaches work for all subareas.

Hopefully, the largely positive results will mean that at least some of these learners will be able to conduct successful and rewarding grammar lessons in their future L2 classrooms.

\section{REFERENCES}

[1] Abell, S. (2008). Twenty years later: Does pedagogical content knowledge remain a useful idea? International Journal of Science Education, 30, 1405-1416.

[2] Akcan, S. \& Tatar, S. (2010). An investigation of the nature of feedback given to pre-service English teachers during their practice teaching experience. Teacher Development, 14(2), 153-172.

[3] Amobi, F. A. (2005). Pre-service teachers' reflectivity on the sequence and consequences of teaching actions in a microteaching experience. Teacher Education Quarterly, 32(1), 115-128.

[4] Bararah, I. (2016). Pedagogical content knowledge for teaching English. English Education Journal, 7(2), 155167.

[5] Bell, N. (2007). Micro-teaching: What is it that is going on here?. Linguistics and Education, 18, 24-40.

[6] Berry, A., Loughran, J. \& Van Dreil, J. H. (2008). Revisiting the roots of pedagogical content knowledge. International Journal of Science Education, 30(10), 1271-1279.

[7] Clark, C. M. \& Peterson, P. L. (1986). Teachers' thought processes. In M. C. Wittrock (Ed.), Second handbook of research on teaching (pp. 255-296). New York, NY: Macmillan.

[8] Clermont, C. P., Borko, H. \& Krajcik, J. S. (1994). Comparative study of the pedagogical content knowledge of experienced and novice chemical demonstrators. Journal of Research in Science Teaching, 31, 419-441.

[9] Cochran, K. F., DeRuiter, J. A. \& King, R. A. (1993). Pedagogical content knowing: An integrative model for teacher preparation. Journal of Teacher Education, 44, 263-272.

[10] Cruickshank, D. R. (1996). Preparing America's teachers. Bloomington, IN: Phi Delta Kappa.

[11] Cuban, L. (1982). Persistence of the inevitable: The teacher centred classroom. Education and Urban Society, 15(1), 26-41.

[12] Darling-Hammond, L. (2006). Assessing teacher education: The usefulness of multiple measures for assessing program outcomes. Journal of Teacher Education, 57, 120-138.

[13] Farrell, T. S. C. (1999). The reflective assignment: Unlocking pre-service English teachers' beliefs on grammar teaching. RELC Journal, 30(2), 1-17.

[14] Farrell, T. S. C. (2007). Reflective language teaching: From research to practice. London, UK: Continuum Press.

[15] Farrell, T. S. C. (2008). 'Here is the book, go teach the class': ELT practicum support. RELC Journal, 39, 226241.

[16] Farrell, T. S. C. (2013a). Reflective teaching. Alexandria, VA, USA: TESOL International Publications.

[17] Farrell, T. S. C. (2013b). Critical incident analysis through narrative reflective practice: A case study. Iranian Journal of Language Teaching Research, 1(1), 79-89.

[18] Farrell, T. S. C. (2014). Reflective practice in ESL teacher development groups: From practice to principles. Basingstoke, UK: Palgrave MacMillan.

[19] Fernandez, M. L. (2010). Investigating how and what prospective teachers learn through micro-teaching lesson study. Teaching and Teacher Education, 26(2), 351-362.

[20] Freeman, D. (2002). The hidden side of the work: Teacher knowledge and learning to teach. Language Teaching, 35(1), 1-13.

[21] Grossman, P. L. (1990). The making of a teacher: Teacher knowledge and teacher education. NY: Teachers College Press.

[22] Grossman, P. L. \& McDonald, M. (2008). Back to the future: Directions for research in teaching and teacher education. American Educational Research Journal, 45, 184-205.

[23] Hadjioannou, X. \& Hutchinson, M. C. (2010). Putting the G back in English: Preparing pre-service teachers to teach grammar. English Teaching: Practice and Critique, 9(3), 90-105.

[24] Hashweh, M. Z. (1987). Effects of subject matter knowledge in the teaching of biology and physics. Teaching and Teacher Education, 3, 109-120.

[25] Hattie, J. \& Timperley, H. (2007) The power of feedback. Review of Educational Research, 77(1), 81-112.

[26] Ismail, S. A. A. (2011). Student teachers' micro-teaching experiences in preservice English teacher education program. Journal of Language Teaching and Research, 2(5), 1043-1051.

[27] Lee, I. (2007). Preparing pre-service English teachers for reflective practice. ELT journal, 61(4), 321-329.

[28] Lee, I. (2017). Classroom writing assessment and feedback in L2 school contexts. Singapore: Springer Verlag.

[29] Liu, S. (2013). Pedagogical content knowledge: A case study of ESL teacher education. English Language Teaching, 6(7), 128138.

[30] McDougall, M. J. (2005). Scaffolded growth of knowledge using distributed collaborative learning tools in preservice teacher education. Unpublished doctoral thesis. Queensland University of Technology, Brisbane.

[31] Mishra, P. \& Koehler, M. J. (2006). Technological pedagogical content knowledge: A new framework for teacher knowledge. Teachers College Record, 108(6), 1017-1054.

[32] Ogeyik, M. C. (2009). Attitudes of the student teachers in English language teaching programs towards micro-teaching technique. English Language Teaching, 2(3), 205-212.

[33] Putnam, R. T. \& Borko, H. (2000). What do new views of knowledge and thinking have to say about research on teacher learning. Educational Researcher, 29(1), 4-15.

[34] Ryan, K. \& Cooper, M. (2004). Those who can, teach. Boston: Houghton Mifflin. 
[35] Shulman, L. S. (1986). Those who understand: Knowledge growth in teaching. Educational Researcher, 15(2), 4-14.

[36] Shulman, L. S. (1987). Knowledge and teaching: Foundations of the new reform. Harvard Educational Review, 57(1), 1-22.

[37] Schön, D. A. (1991). The reflective practitioner: How professionals think in action. New York, NY: Basic Books.

[38] Ur, P. (1996). A course in English language teaching: Practice and theory. Cambridge: Cambridge University Press.

[39] Wiggins, G. (1993). Assessing student performance. San Francisco: Jossey-Bass.

[40] Williamson, J. \& Hardman, F. (1995). Time for refilling the bath?: A study of primary student-teachers' grammatical knowledge. Language and Education, 9(2), 117-134.

[41] Wilson, J. P. (2008). Reflecting-on-the-future: A chronological consideration of reflective practice. Reflective Practice: International and Multidisciplinary Perspectives, 9, 177-184.

Monica Karlsson is Associate Professor of English at Halmstad University, Sweden. Her main field of interest is Second Language Acquisition in the area of which she has published several research articles and books, the most recent one being Idiomatic mastery in a first and second language published by Multilingual Matters. 